\title{
Azithromycin to Prevent Pertussis in Household Contacts, Catalonia and Navarre, Spain, 2012-2013
}

\author{
Josep Alvarez, Pere Godoy, Pedro Plans-Rubio, Neus Camps, Monica Carol, \\ Gloria Carmona, Ruben Solano, Cristina Rius, Sofia Minguell, Irene Barrabeig, \\ Maria R. Sala-Farré, Raquel Rodriguez, Manuel Garcia-Cenoz, Carmen Muñoz-Almagro, \\ Angela Dominguez, Transmission of Pertussis in Households Working Group ${ }^{1}$
}

We retrospectively assessed the effectiveness of azithromycin in preventing transmission of pertussis to a patient's household contacts. We also considered the duration between symptom onset in the primary patient and azithromycin administration. We categorized contacts into 4 groups: those treated within $\leq 7$ days, 8-14 days, 15-21 days, and $>21$ days after illness onset in the primary patient. We studied 476 primary index patients and their 1,975 household contacts, of whom $4.5 \%$ were later identified as having pertussis. When contacts started chemoprophylaxis within $\leq 21$ days after the primary patient's symptom onset, the treatment was $43.9 \%$ effective. Chemoprophylaxis started $>14$ days after primary patient's symptom onset was less effective. We recommend that contacts of persons with pertussis begin chemoprophylaxis within $\leq 14$ days after primary patient's symptom onset.

fter decades of decline $(1,2)$ and despite high Avaccination coverage, the incidence of pertussis has increased substantially in Catalonia, Spain $(3,4)$; Spain (5); and other regions and countries with wellestablished epidemiologic surveillance systems (6).

Author affiliations: Agència de Salut Pública de Catalunya,

Barcelona, Spain (J. Alvarez, P. Godoy, P. Plans-Rubio,

N. Camps, M. Carol, G. Carmona, S. Minguell, I. Barrabeig, M.R. Sala-Farré, R. Rodriguez); Institut de Recerca Biomédica de Lleida, Leida, Spain (P. Godoy); Consorcio de Investigación Biomédica en Red de Epidemiología y Salud Pública (CIBERSP), Madrid, Spain (P. Godoy, P. Plans-Rubio, R. Solano, C. Rius, I. Barrabeig, M. García Cenoz, C. Muñoz-Almagro, A. Domínguez) Agència de Salut Pública de Barcelona, Barcelona (R. Solano, C. Rius); Instituto de Salud Pública de Navarra, Pamplona, Spain

(M. Garcia-Cenoz); Hospital de Sant Joan de Deu, Barcelona

(C. Muñoz-Almagro); Universitat de Barcelona, Barcelona

(A. Dominguez)

DOI: https://doi.org/10.3201/eid2611.181418
Many researchers attribute this pattern to an increasingly waning immunity in persons vaccinated with the acellular vaccines currently used in most countries instead of the whole-cell vaccines used until the late 1990s (7-11).

The causative agent of pertussis, Bordatella pertussis, is mainly spread through household contacts $(12,13)$. However, guidelines contain few measures to prevent intrahousehold transmission. Most guidelines recommend patient isolation, vaccination of children $<7$ years of age, and chemoprophylaxis for household members and other frequent contacts $(14,15)$. Generally, guidelines recommend that household contacts begin chemoprophylaxis with a macrolide within 21 days after symptom onset in the index patient. However, evidence of its effectiveness in preventing transmission is limited $(16,17)$. In addition, there is a lack of studies on the effectiveness of azithromycin, because studies on chemoprophylaxis for pertussis usually use erythromycin $(18,19)$.

A study of pertussis patients in Catalonia and Navarre, 2 autonomous communities in Spain, assessed the overall effectiveness of azithromycin in preventing transmission among household contacts (20). After adjustment for age, sex, vaccination history, and relationship to the primary patient, chemoprophylaxis had an adjusted effectiveness of $62.1 \%$ in this study, consistent with the results of other studies (21). However, this study cohort (20) included 164 nonprimary index patients (i.e. patients with the first reported case of pertussis in a household, but not the first chronological case) and their 877 contacts, did not consider the duration between symptom onset in the primary patient and start of treatment, and did

${ }^{1}$ Members of the Transmission of Pertussis in Households Working Group who contributed data are listed at the end of this article. 
not exclude co-primary and tertiary patients (who might not have been infected by the primary patient) (20). We assessed whether delays in chemoprophylaxis reduce its effectiveness.

\section{Materials and Methods}

The study cohort comprised the household contacts of primary index patients with pertussis detected by the Epidemiologic Surveillance Units (ESU) of Catalonia and Navarre from January 1, 2012, through December 31,2013 . We followed up on the household contacts 28 days after symptom onset in the index patient.

The index patient was the first patient with pertussis reported to the ESU in each household and the primary patient was the first patient with pertussis in each household, regardless of whether or when his or her case had been reported. In most situations, the index and primary patients were the same person; for our study, we excluded instances when the index and primary patients were different persons. The ESU prescribed the postexposure intervention for every index patient and their contacts. Our study included only patients with $B$. pertussis infection confirmed by culture or real-time PCR of nasopharyngeal samples. We categorized household contacts as persons regularly living in the same household or persons in the home for $>2$ hours during the transmission period ( $\leq 21$ days after symptom onset in the primary patient or $\leq 5$ days after the patient's start of treatment).

ESU staff conducted telephone interviews to gather information about each contact's age, sex, relationship to the index or primary patient, receipt of chemoprophylaxis and start date, vaccination history, and presence of pertussis symptoms (cough lasting $\geq 2$ weeks, paroxysmal cough, posttussive vomiting, inspiratory stridor, and apnea). Staff collected vaccination statuses and laboratory results (i.e., culture assay, PCR) from the contacts' medical records and determined a person's vaccination status using the vaccination records of each autonomous community. We categorized each contact as fully vaccinated $(\geq 4$ doses of vaccine), incompletely vaccinated $(<4$ doses), unvaccinated (no dose), incompletely vaccinated because of age (i.e. children $<18$ months of age who had received recommended doses), and unvaccinated because of age (i.e. children $<2$ months of age). Because few contacts $>18$ years of age had vaccination records, we analyzed this variable only in contacts $\leq 18$ years of age.

At 28 days after symptom onset in the primary patient, we categorized contacts as follows: healthy contact, no clinical symptoms of pertussis; primary patient, the first patient at a specific address (this might differ from the index patient, who had the first reported case); co-primary patient, symptom onset within $\leq 6$ days of the primary patient; secondary patient, symptom onset within 7-28 days after the primary patient; and tertiary patient, symptom onset within $>28$ days after the primary patient. Before administering treatment, ESU staff took nasopharyngeal samples of each patient and their contacts with possible pertussis symptoms. We considered symptomatic contacts as patients when we confirmed their diagnosis by culture or real-time PCR or found an epidemiologic link (onset of symptoms $\leq 28$ days later) with a laboratory-confirmed case.

We evaluated the characteristics of persons who did or did not receive chemoprophylaxis using $\chi^{2}$ (for categorical variables) and Student $t$-test (for continuous variables). We then studied the effectiveness of chemoprophylaxis in preventing pertussis in persons classified as healthy contacts or secondary patients after 28 days of follow-up. We excluded co-primary and tertiary patients from the analysis because they might not have been infected by primary patients.

We calculated the effectiveness of azithromycin for 5 days using the formula effectiveness $=(1-$ relative risk) $\times 100$. We considered effectiveness according to the duration between symptom onset in the primary patient and start of chemoprophylaxis. We classified this duration into 4 categories: 1-7 days, 8-14 days, 15-21 days, and $>21$ days after illness onset in the primary patient.

We used unconditional logistic regression to estimate effectiveness adjusted by vaccination status. We also assessed effectiveness according to the age of contacts ( $<1$ year, 1 year, 2-3 years, $4-6$ years, $7-10$ years, $11-18$ years, $19-40$ years, and $>40$ years of age), degree of relationship (cohabitants vs. persons in the home $>2$ hours), and type of relationship with the primary index patient (mother, father, sibling, grandparent, spouse, child, and other). We analyzed the data using SPSS Statistics 18.0 (IBM, https://www.ibm. com), and Epi Info (Centers for Disease Control and Prevention, https:/ / www.cdc.gov).

The Ethics Committee of the Hospital Sant Joan de Deu approved the study (code: PIC-79-11). All contacts and family members gave informed written consent to participate.

\section{Results}

From January 1, 2012, through December 31, 2013, the ESU detected 688 cases of pertussis, of which $524(76.2 \%)$ were primary index cases. Of these, 476 $(90.8 \%)$ case-patients had reported data on the administration and outcome of chemoprophylaxis for 
2,051 contacts. We excluded 76 contacts because they were co-primary patients (65 persons) or tertiary patients (11 persons). Therefore, our final study consisted of 1,975 household contacts of 476 primary index patients (hereafter primary patients).

Of the 1,975 contacts we analyzed, 53.5\% were female. The mean age was 33.9 (SD \pm 20.5 ) years; $2.2 \%$ of contacts were $<1$ year of age (the most vulnerable group), $34.7 \%$ were $19-40$ years of age, and $35.4 \%$ were $>40$ years of age. A total of $76.5 \%$ of contacts lived with the primary patient; $23.4 \%$ of contacts were mothers, $21.5 \%$ were fathers, and $19.6 \%$ were siblings of the primary patient (Table 1). Most of the 591 contacts $\leq 18$ years of age were completely vaccinated $(65.7 \%$ had received $\geq 4$ doses and $6.1 \%$ were completely vaccinated in accordance with recommendations for their age).

Of the $1,720(87.1 \%)$ contacts who received chemoprophylaxis, 1,266 (73.6\%) were treated within $\leq 21$ days after symptom onset of the primary patient: $309(18 \%)$ were treated within $\leq 7$ days, 544 (31.6\%) within 8-14 days, 413 (24\%) within 15-21 days, and $393(22.8 \%)$ in $>21$ days. At 28 days after symptom onset in the primary patient, pertussis had developed in $4.5 \%$ of contacts, including $1 \%$ of those who had received chemoprophylaxis $\leq 7$ days and $7.6 \%$ of those who received it $>21$ days after symptom onset in the primary patient (Figure). The 1,720 (87.1\%) contacts

\begin{tabular}{|c|c|c|c|c|}
\hline \multirow[b]{2}{*}{ Characteristic } & \multirow[b]{2}{*}{ Contacts* } & \multicolumn{2}{|c|}{ Received chemoprophylaxis* } & \multirow[b]{2}{*}{$\mathrm{p}$ value } \\
\hline & & Yes & No & \\
\hline Total & $1,975(100)$ & $1,720(87.1)$ & $255(12.9)$ & \\
\hline \multicolumn{5}{|l|}{ Sex } \\
\hline M & $919(46.5)$ & 797 (46.3) & $122(47.8)$ & 0.64 \\
\hline $\mathrm{F}$ & $1,056(53.5)$ & $923(53.7)$ & $133(52.2)$ & \\
\hline \multicolumn{5}{|l|}{ Age, y } \\
\hline$<1$ & $44(2.2)$ & $41(2.4)$ & $3(1.2)$ & 0.67 \\
\hline 1 & $33(1.7)$ & $33(1.9)$ & $0(0.0)$ & \\
\hline $2-3$ & $79(4.0)$ & $67(3.9)$ & $12(4.7)$ & \\
\hline $4-6$ & $132(6.7)$ & $120(7.0)$ & $12(4.7)$ & \\
\hline $7-10$ & $154(7.8)$ & $135(7.8)$ & $19(7.5)$ & \\
\hline $11-18$ & $149(7.5)$ & $131(7.6)$ & $18(7.1)$ & \\
\hline $19-40$ & $685(34.7)$ & $595(34.6)$ & $90(35.3)$ & \\
\hline$>40$ & $699(35.4)$ & $598(34.8)$ & $101(39.6)$ & \\
\hline Mean age, y $( \pm S D)$ & $33.9(20.5)$ & $33.4(20.5)$ & $37.3(20.6)$ & $0.005 \ddagger$ \\
\hline Median age, $\mathrm{y}$ & 36 & 36 & 39 & \\
\hline \multicolumn{5}{|l|}{ Type of household contact } \\
\hline Household cohabitant & $1,511(76.5)$ & $1,311(76.2)$ & $200(78.4)$ & 0.44 \\
\hline Other $>2 \mathrm{~h}$ & $464(23.5)$ & $409(23.8)$ & $55(21.6)$ & \\
\hline \multicolumn{5}{|l|}{ Relationship to primary patient } \\
\hline Mother & $463(23.4)$ & $400(23.3)$ & $63(24.7)$ & 0.69 \\
\hline Father & $424(21.5)$ & $366(21.3)$ & $58(22.7)$ & \\
\hline Sibling & $388(19.6)$ & $352(20.5)$ & $36(14.1)$ & \\
\hline Grandparent & $281(14.2)$ & $248(14.4)$ & 33 (12.9) & \\
\hline Child & $19(1.0)$ & $15(0.9)$ & $4(1.6)$ & \\
\hline Spouse & $26(1.3)$ & $20(1.2)$ & $6(2.4)$ & \\
\hline Other & $374(18.9)$ & $319(18.5)$ & $55(21.6)$ & \\
\hline Vaccination status $\leq 18 \mathrm{y}$ & 591 & 527 & 64 & \\
\hline Fully vaccinated ( $\geq 4$ doses) & $388(65.7)$ & $349(66.2)$ & $39(60.9)$ & 0.36 \\
\hline Incomplete for age & $36(6.1)$ & $35(6.6)$ & $1(1.6)$ & \\
\hline Incomplete & $16(2.7)$ & $15(2.8)$ & $1(1.6)$ & \\
\hline Not vaccinated & $24(4.1)$ & $21(4.0)$ & $3(4.7)$ & \\
\hline Too young for vaccination & $5(0.8)$ & $4(0.8)$ & $1(1.6)$ & \\
\hline Not stated & $122(20.6)$ & $103(19.5)$ & $19(29.7)$ & \\
\hline \multicolumn{5}{|l|}{ Chemoprophylaxis initiation, $d \S$} \\
\hline $1-7$ & $309(15.6)$ & $309(18.0)$ & 0 & \\
\hline $8-14$ & $544(27.5)$ & $544(31.6)$ & 0 & \\
\hline $15-21$ & 413 (20.9) & $413(24.0)$ & 0 & \\
\hline$>21$ & $393(19.9)$ & $393(22.8)$ & 0 & \\
\hline Unknown & $61(3.1)$ & $61(3.5)$ & 0 & \\
\hline No chemoprophylaxis & $255(12.9)$ & $255(14.8)$ & 0 & \\
\hline \multicolumn{5}{|l|}{ Type of contact } \\
\hline Healthy contact & $1,886(95.5)$ & $1,645(95.6)$ & $241(94.5)$ & 0.44 \\
\hline Secondary case & $89(4.5)$ & $75(4.4)$ & $14(5.5)$ & \\
\hline
\end{tabular}

*Values are no. (\%) except as indicated.

tp value for $\chi^{2}$ test.

$\neq \mathrm{p}$ value for Student $t$-test.

$\S$ Days after symptom onset of the primary patient. 


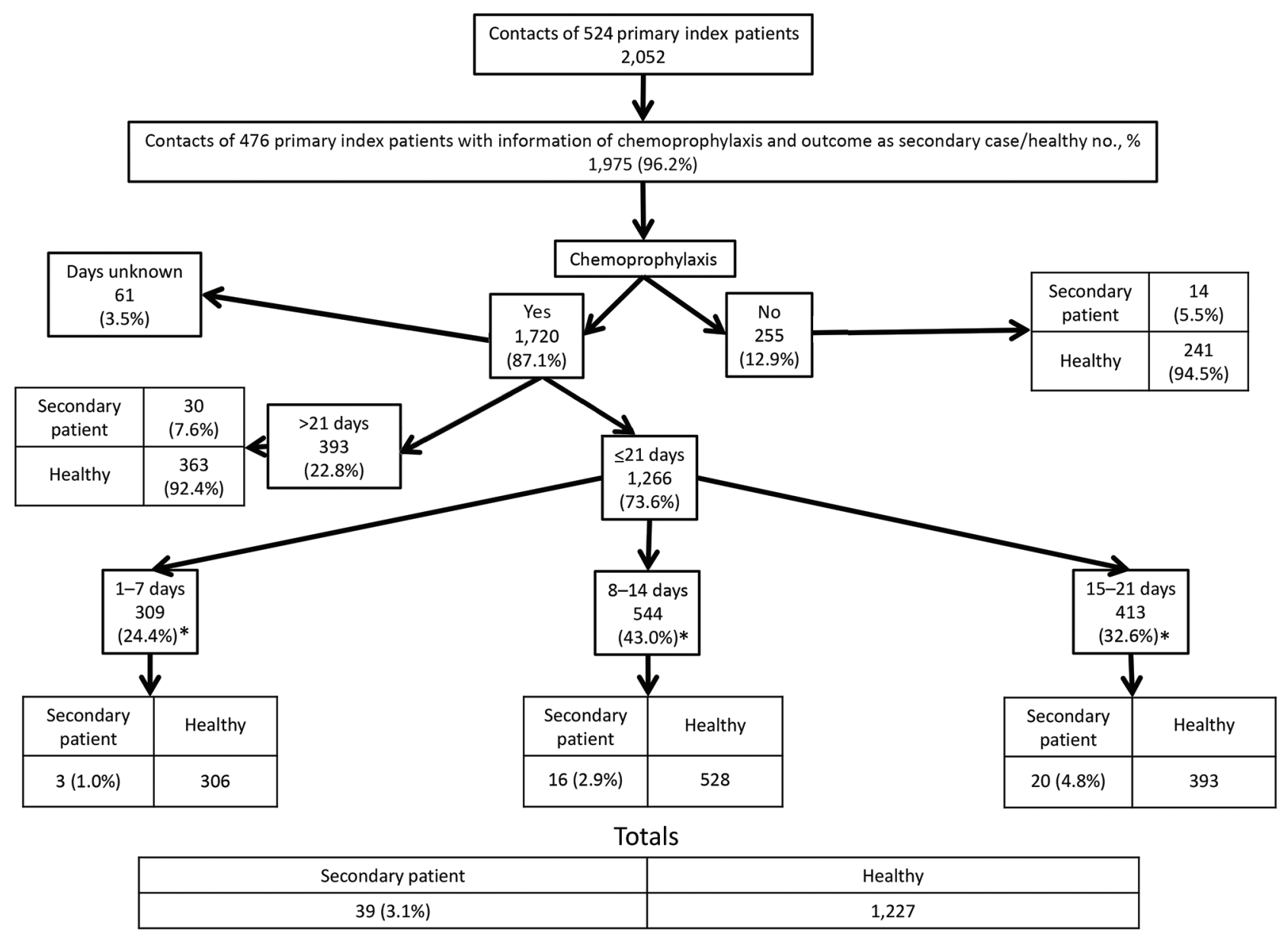

Figure. Flowchart of study of effectiveness of chemoprophylaxis in preventing pertussis transmission among household contacts of primary index patients, Catalonia and Navarre, Spain, 2012-2013. *Pooled data.

who received and $255(12.9 \%)$ who did not receive chemoprophylaxis differed significantly only by mean age (33.4 vs. 37.3 years) and being a sibling of the primary patient (20.5\% vs. $14.1 \%)$ (Table 1$)$.

Chemoprophylaxis was $43.9 \%$ (95\% CI $-1.8 \%$ to $69.1 \%$ ) effective when administered $\leq 21$ days after symptom onset in the primary patient. Chemoprophylaxis was ineffective $(-39.0 \%$ [ $95 \%$ CI $-157.0 \%$ to $25.0 \%]$ ) when administered after $>21$ days (Table 2 ).

Of contacts $\leq 18$ years of age, $87.6 \%(298 / 340)$ received chemoprophylaxis, which was $44.1 \%$ (95\% CI $-42.2 \%$ to $77.7 \%)$ effective. Comparison of contacts $\leq 18$ years of age who did and did not receive chemoprophylaxis within $\leq 21$ days showed that chemoprophylaxis was $44.1 \%$ (95\% CI $-59.5 \%$ to $80.4 \%$ ) effective in completely vaccinated persons (e4 doses) and $50 \%$ (95\% CI $-248.0 \%$ to $92.8 \%)$ effective in incompletely vaccinated persons. This difference was not significant, although the statistical power was very low $(16 \%$ for completely vaccinated and $8 \%$ for unvaccinated persons) (Table 2).
Overall, in comparison with results for contacts who did not receive chemoprophylaxis, the treatment had an effectiveness of $82.3 \%$ (95\% CI 39.1\%-94.9\%) for contacts who received it within $\leq 7$ days, $46.4 \%$ (95\% CI $-8.1 \%$ to $73.4 \%$ ) for those who received it within $8-14$ days, and $11.8 \%$ (95\% CI $-71.5 \%$ to $54.6 \%$ ) for those who received it within 15-21 days. When we adjusted the results by vaccination history, we found the reduction over time resembled the declining effectiveness (Table 3).

\section{Discussion}

Most guidelines recommend that contacts take chemoprophylaxis with azithromycin $\leq 21$ days after symptom onset in the index patient $(14,22-24)$. By only including primary index cases, our study more precisely assessed the effectiveness of chemoprophylaxis in preventing household transmission.

Chemoprophylaxis had an overall effectiveness of $43.9 \%$ (95\% CI $-1.8 \%$ to $69.1 \%$ ), lower than the $62.1 \%$ found in the previous study in Catalonia and 
Table 2. Effectiveness of chemoprophylaxis to prevent pertussis transmission among 1,975 household contacts, Catalonia and Navarre, Spain, 2012-2013

\begin{tabular}{|c|c|c|c|c|}
\hline \multirow[b]{2}{*}{ Chemoprophylaxis timing for contacts* } & \multirow[b]{2}{*}{ No. contacts } & \multicolumn{2}{|c|}{ Type of contact } & \multirow[b]{2}{*}{ Effectiveness, \% (95\% Cl) } \\
\hline & & $\begin{array}{c}\text { Healthy contact, } \\
\text { no. }(\%)\end{array}$ & $\begin{array}{c}\text { Secondary case- } \\
\text { patient, no. (\%) }\end{array}$ & \\
\hline All & 1,914 & $1831(95.7)$ & $64(3.3)$ & \\
\hline $1-21 d$ & 1,266 & 1,227 (96.9) & $39(3.1)$ & $43.9(-1.8$ to 69.1$)$ \\
\hline$>21 d$ & 393 & $363(92.4)$ & $30(7.6)$ & $-39.0(-157.0$ to 25.0$)$ \\
\hline No chemoprophylaxis & 255 & $241(94.5)$ & $14(5.5)$ & Reference \\
\hline \multicolumn{5}{|l|}{ Completely vaccinated } \\
\hline $1-21 d$ & 248 & $233(94.0)$ & $15(6.0)$ & $44.1(-59.5$ to 80.4$)$ \\
\hline No chemoprophylaxis & 37 & $33(89.2)$ & $4(10.8)$ & Reference \\
\hline \multicolumn{5}{|l|}{ Incompletely vaccinated } \\
\hline $1-21 d$ & 50 & $45(90.0)$ & $5(10.0)$ & $50.0(-248.0,92.8)$ \\
\hline No chemoprophylaxis & 5 & $4(80.0)$ & $1(20.0)$ & Reference \\
\hline
\end{tabular}

Navarre (20). The effectiveness was highest when given during the first 7 days after symptom onset in the primary patient and fell significantly with increased treatment delays.

Our results reinforce the ineffectiveness $(14,24)$ ( $-39.0 \%$ [ $95 \% \mathrm{CI}-157.0 \%$ to $25.0 \%])$ of administering chemoprophylaxis $>21$ days after symptom onset in the primary patient. Chemoprophylaxis also had a low effectiveness when administered after 14 days. Our results indicate that chemoprophylaxis should be started $\leq 14$ days after symptom onset in the primary patient; however, this recommendation conflicts with the established clinical definition of pertussis, which describes a cough lasting $\geq 2$ weeks $(22,25)$. Therefore, we recommend that chemoprophylaxis should start immediately after the ESU is alerted to the possibility of pertussis, without waiting for a laboratory-confirmed diagnosis.

Perhaps because of the small number of persons in each category, effectiveness was not associated with age, vaccination status, degree of home contact, or relationship with the primary patient. However, confounding variables might influence the (lack of) association between vaccination status and chemoprophylaxis effectiveness; for example, vaccine effectiveness might wane in some age groups or be bolstered in persons not cohabiting (i.e., point contact instead of prolonged contact) with the primary patient. The effectiveness of chemoprophylaxis should be more closely investigated in children $<1$ year of age, in whom pertussis is particularly serious.

Our finding that azithromycin was ineffective when administered $>14$ days after symptom onset in the primary patient suggests that physicians should not initiate chemoprophylaxis after that time. This strategy might reduce costs, potential adverse effects, and risk for azithromycin resistance (26-28).

The limited effectiveness of chemoprophylaxis in reducing pertussis transmission highlights the importance of patient isolation until 21 days after symptom onset, or 5 days after treatment initiation $(22,24)$. Furthermore, communities should strive for high vaccination coverage; physicians should review the vaccination status of contacts; and physicians should regularly update the vaccination schedule, as recommended by some guidelines (22). These measures are especially important when a patient with pertussis has contact with children $<1$ year of age; pregnant women; immunosuppressed persons; and persons with chronic diseases, such as asthma, cystic fibrosis, or congenital heart disease (6).

Our study was subject to several limitations. It lacked the statistical power to estimate the effectiveness of chemoprophylaxis in terms of contact age, degree of home contact, and relationship with the primary patient. We used self-reported data on treatment, so we cannot verify whether contacts complied with treatment. We also cannot rule out the possibility

Table 3. Effect of delay in chemoprophylaxis on preventing pertussis transmission among 1,975 household contacts, Catalonia and Navarre, Spain, 2012-2013

\begin{tabular}{|c|c|c|c|c|c|}
\hline \multirow[b]{2}{*}{$\begin{array}{l}\text { Chemoprophylaxis for contacts, } \\
d^{*}\end{array}$} & \multirow[b]{2}{*}{$\begin{array}{c}\text { No. } \\
\text { contacts }\end{array}$} & \multicolumn{2}{|c|}{ Type of contact } & \multirow[b]{2}{*}{$\begin{array}{l}\text { Effectiveness, \% } \\
(95 \% \mathrm{Cl})\end{array}$} & \multirow[b]{2}{*}{$\begin{array}{c}\text { Adjusted effectiveness, } \\
\% \dagger(95 \% \mathrm{Cl})\end{array}$} \\
\hline & & $\begin{array}{l}\text { Healthy contact, } \\
\text { no. }(\%)\end{array}$ & $\begin{array}{c}\text { Secondary case- } \\
\text { patient, no. (\%) }\end{array}$ & & \\
\hline $1-7$ & 309 & $306(99.0)$ & $3(1.0)$ & $82.3(39.1,94.9)$ & $89.0(6.7,98.7)$ \\
\hline $8-14$ & 544 & $528(97.1)$ & $16(2.9)$ & $46.4(-8.1$ to 73.4$)$ & $37.2(-114.9$ to 75.4$)$ \\
\hline $15-21$ & 413 & $393(95.2)$ & $20(4.8)$ & $11.8(-71.5$ to 54.6$)$ & $2.8(-171.3$ to 65.2$)$ \\
\hline No chemoprophylaxis & 255 & $241(94.5)$ & $14(5.5)$ & & ferent \\
\hline
\end{tabular}

${ }^{*}$ No. days after symptom onset in primary patient whose contacts received chemoprophylaxis.

†Adjusted by vaccination status. 
that undetected infected persons could have altered transmission dynamics. Finally, confirmatory laboratory testing was not conducted for $40.4 \%$ of secondary patients. However, we believe the probability of misclassification is very low.

In conclusion, our results show azithromycin chemoprophylaxis for pertussis had low effectiveness when initiated $>14$ days after symptom onset in the primary patient. Therefore, public health services should expedite chemoprophylaxis in homes where contacts of suspected patients have risk factors for this disease.

Members of the Transmission of Pertussis in Households Working Group who contributed data are Miquel Alsedà, Josep Alvarez, Cesar Arias, Irene Barrabeig, Neus Camps, Glòria Carmona, Mónica Carol, Maria Company, Joaquim Ferràs, Glòria Ferrús, Pere Godoy, Mireia Jané, Sofia Minguell, Pedro Plans, Raquel Rodríguez, María-Rosa Sala, Roser Torra, Inma Crespo, Diana Toledo, Àngela Domínguez, Rubén Solano, Joan Caylà, Sara Lafuente, Cristina Rius, Manuel García Cenoz, Rosana Burgui, Jesús Castilla, Pedro Brotons, Iolanda Jordan, and Carmen Muñoz-Almagro.

This study was funded by the Carlos III Health Institute through project nos. PI11/02557 and PI15/01348 (cofunded by European Regional Development Fund "Investing in your future" program) and the Catalan Agency for the Management of University Grants (grant no. 2017/SGR 1342).

\section{About the Author}

Dr. Alvarez is head of the Epidemiological Surveillance Service, Catalonia Public Health Agency, Barcelona. His primary research interests are community-acquired Legionnaires' disease, tuberculosis, and the spread of pertussis in households.

\section{References}

1. World Health Organization Strategic Advisory Group of Experts Pertussis Working Group. Background paper [cited 2020 Feb 9]. http:/ / www.who.int/immunization/ sage/meetings/2014/april/1_Pertussis_background_ FINAL4_web.pdf?ua=

2. Tan T, Dalby T, Forsyth K, Halperin SA, Heininger U, Hozbor D, et al. Pertussis across the globe: recent epidemiologic trends from 2000 to 2013. Pediatr Infect Dis J. 2015;34:e222-32. https://doi.org/10.1097/INF.0000000000000795

3. Crespo I, Cardeñosa N, Godoy P, Carmona G, Sala MR, Barrabeig I, et al. Epidemiology of pertussis in a country with high vaccination coverage. Vaccine. 2011;29:4244-8. https:/ / doi.org/10.1016/j.vaccine.2011.03.065

4. Sala-Farré MR, Arias-Varela C, Recasens-Recasens A, Simó-Sanahuja M, Muñoz-Almagro C, Pérez-Jové J. Pertussis epidemic despite high levels of vaccination coverage with acellular pertussis vaccine. Enferm Infecc Microbiol Clin. 2015;33:27-31. https:// doi.org/10.1016/j.eimc.2013.09.013

5. Sizaire V, Garrido-Estepa M, Masa-Calles J, Martinez de Aragon MV. Increase of pertussis incidence in 2010 to 2012 after 12 years of low circulation in Spain. Euro Surveill. 2014;19:20875. https:/ / doi.org/10.2807/1560-7917. ES2014.19.32.20875

6. Hartzell JD, Blaylock JM. Whooping cough in 2014 and beyond: an update and review. Chest. 2014;146:205-14. https://doi.org/10.1378/chest.13-2942

7. Witt MA, Katz PH, Witt DJ. Unexpectedly limited durability of immunity following acellular pertussis vaccination in preadolescents in a North American outbreak. Clin Infect Dis. 2012;54:1730-5. https:/ / doi.org/10.1093/ cid/cis287

8. Clark TA. Changing pertussis epidemiology: everything old is new again. J Infect Dis. 2014;209:978-81. https:// doi.org/ 10.1093/infdis/jiu001

9. Clark TA, Messonnier NE, Hadler SC. Pertussis control: time for something new? Trends Microbiol. 2012;20:211-3. https:// doi.org/10.1016/j.tim.2012.03.003

10. Klein NP, Bartlett J, Fireman B, Rowhani-Rahbar A, Baxter R. Comparative effectiveness of acellular versus whole-cell pertussis vaccines in teenagers. Pediatrics. 2013;131:e1716-22. https:/ / doi.org/10.1542/peds.2012-3836

11. Klein NP, Bartlett J, Rowhani-Rahbar A, Fireman B, Baxter R. Waning protection after fifth dose of acellular pertussis vaccine in children. N Engl J Med. 2012;367:1012-9. https:// doi.org/10.1056/NEJMoa1200850

12. Wendelboe AM, Njamkepo E, Bourillon A, Floret DD, Gaudelus J, Gerber M, et al.; Infant Pertussis Study Group. Transmission of Bordetella pertussis to young infants. Pediatr Infect Dis J. 2007;26:293-9. https:/ / doi.org/10.1097/ 01.inf.0000258699.64164.6d

13. Kowalzik F, Barbosa AP, Fernandes VR, Carvalho PR, Avila-Aguero ML, Goh DYT, et al. Prospective multinational study of pertussis infection in hospitalized infants and their household contacts. Pediatr Infect Dis J. 2007;26:238-42. https:/ / doi.org/10.1097/01.inf.0000256750.07118.ee

14. Tiwari T, Murphy TV, Moran J; National Immunization Program, CDC. Recommended antimicrobial agents for the treatment and postexposure prophylaxis of pertussis: 2005 CDC Guidelines. MMWR Recomm Rep. 2005; 54(RR-14):1-16.

15. Dodhia H, Crowcroft NS, Bramley JC, Miller E. UK guidelines for use of erythromycin chemoprophylaxis in persons exposed to pertussis. J Public Health Med. 2002;24:200-6. https:// doi.org/10.1093/pubmed/24.3.200

16. Altunaiji SM, Kukuruzovic RH, Curtis NC, Massie J. Antibiotics for whooping cough (pertussis) [review]. Cochrane Database Syst Rev. 2007;3:CD004404.

17. Goins WP, Edwards KM, Vnencak-Jones CL, Rock MT, Swift M, Thayer V, et al. A comparison of 2 strategies to prevent infection following pertussis exposure in vaccinated healthcare personnel. Clin Infect Dis. 2012;54:938-45. https://doi.org/10.1093/cid/cir973

18. Halperin SA, Bortolussi R, Langley JM, Eastwood BJ, De Serres G. A randomized, placebo-controlled trial of erythromycin estolate chemoprophylaxis for household contacts of children with culture-positive bordetella pertussis infection. Pediatrics. 1999;104:e42. https:// doi.org/10.1542/ peds.104.4.e42

19. Langley JM, Halperin SA, Boucher FD, Smith B; Pediatric Investigators Collaborative Network on Infections in Canada (PICNIC). Azithromycin is as effective as and better tolerated 
than erythromycin estolate for the treatment of pertussis Pediatrics. 2004;114:e96-101. https:/ / doi.org/10.1542/ peds.114.1.e96

20. Godoy P, García-Cenoz M, Toledo D, Carmona G, Caylà JA, Alsedà M, et al.; Transmission of Pertussis in Households Working Group. Factors influencing the spread of pertussis in households: a prospective study, Catalonia and Navarre, Spain, 2012 to 2013. Euro Surveill. 2016;21:24-33. https://doi.org/10.2807/1560-7917.ES.2016.21.45.30393

21. Baptista PN, Magalhães VS, Rodrigues LC. Children with pertussis inform the investigation of other pertussis cases among contacts. BMC Pediatr. 2007;7:21. https://doi.org/ 10.1186/1471-2431-7-21

22. Haut Conseil de la Santé Publique. Conduit â tenir devant un ou plusieurs cas de coqueluche [cited 2019 Nov 11]. http:/ / www.sante.gouv.fr/IMG/pdf/hcspr20140710_ conduitenircascoqueluche.pdf

23. Public Health England. Guidelines for the public health management of pertussis in England [cited 2019 Nov 11] https://www.gov.uk/government/uploads/system/ uploads/attachment_data/file/541694/Guidelines_for_ the_Public_Health_management_of_Pertussis_in_ England.pdf

24. Britton PH, Jones CA. Pertussis prophylaxis. Aust Prescr. 2012;35:82-4. https://doi.org/10.18773/austprescr.2012.036
25. The European Commission. Commission implementing decision (EU) 2018/945 of 22 June 2018 on the communicable diseases and related special health issues to be covered by epidemiological surveillance as well as relevant case definitions [cited 2020 702/09]. https:/ / eur-lex.europa.eu/legal-content/ $\mathrm{EN} / \mathrm{TXT} / \mathrm{PDF} /$ ?uri=CELEX:32018D0945\&from $=$ EN\#page $=32$

26. Pour AM, Allensworth CD, Clark TA, Liang JL, Cullison P, Messonnier ML, et al.; Centers for Disease Control and Prevention (CDC). Local health department costs associated with response to a school-based pertussis outbreak -Omaha, Nebraska, September-November 2008. MMWR Morb Mortal Wkly Rep. 2011;60:5-9.

27. Thampi N, Gurol-Urganci I, Crowcroft NS, Sander B. Pertussis post-exposure prophylaxis among household contacts: a cost-utility analysis. PLoS One. 2015;10:e0119271. https://doi.org/10.1371/journal.pone.0119271

28. Wang Z, Li Y, Hou T, Liu X, Liu Y, Yu T, et al. Appearance of macrolide-resistant Bordetella pertussis strains in China. Antimicrob Agents Chemother. 2013;57:5193-4. https://doi.org/10.1128/AAC.01081-13

Address for correspondence: Pere Godoy, Departament de Salut, Epidemiología Alcalde Rovira Roure 2 Lleida, Lleida 25006 Spain; email: pere.godoy@gencat.cat

\section{The Public Health Image Library (PHIL)}
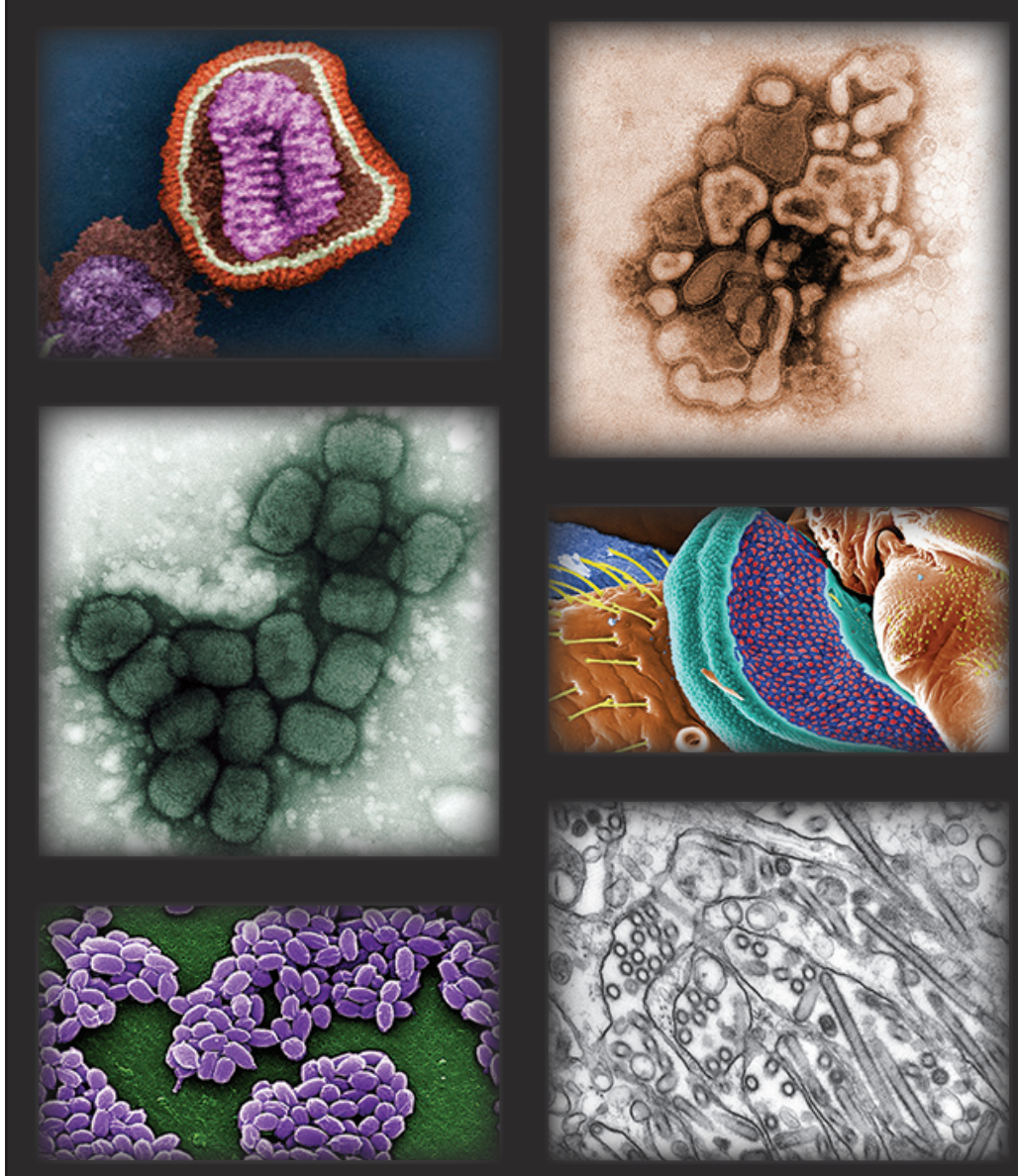

The Public Health Image Library

(PHIL), Centers for Disease

Control and Prevention, contains

thousands of public health-related

images, including high-resolution

(print quality) photographs,

illustrations, and videos.

PHIL collections illustrate current

events and articles, supply visual

content for health promotion

brochures, document the effects

of disease, and enhance

instructional media.

PHIL images, accessible to PC and Macintosh users, are in the public domain and available without charge.

Visit PHIL at http://phil.cdc.gov/phil 